\title{
Effect of Peroxide Loading on Properties of Natural Rubber and Low-density Polyethylene Composites
}

\author{
Wickramage Don Manjula Sampath, ${ }^{1,2^{*}}$ Shantha Maduwage Egodage ${ }^{2}$ \\ and Dilhara Githanjali Edirisinghe ${ }^{1}$ \\ ${ }^{1}$ Rubber Research Institute of Sri Lanka, Telawala Road, \\ 10390 Ratmalana, Sri Lanka \\ ${ }^{2}$ Department of Chemical and Process Engineering, University of Moratuwa, \\ 10400 Moratuwa, Sri Lanka \\ *Corresponding author: wikcramage@yahoo.com
}

Published online: 25 November 2019

To cite this article: Sampath, W. D. M., Egodage, S. \& Edirisinghe, D. G. (2019). Effect of peroxide loading on properties of natural rubber and low-density polyethylene composites. J. Phys. Sci., 30(3), 49-69, https://doi.org/10.21315/jps2019.30.3.4

To link to this article: https://doi.org/10.21315/jps2019.30.3.4

\begin{abstract}
Natural rubber (NR)/low density polyethylene (LDPE) composites are utilised to manufacture rubber-based articles. Properties of these composites become inferior if they are used alone due to the incompatibility of the base polymers. Peroxides help to cross-link both NR and LDPE, and the addition of peroxide to the composite at its optimum loading may enhance properties by developing a stable phase morphology. Therefore, the present work investigates the effect of dicumyl peroxide (DCP) loading on physicomechanical properties of calcium carbonate $\left(\mathrm{CaCO}_{3}\right)$-filled $\mathrm{NR} / \mathrm{LDPE}(70 / 30)$ composites. The composite preparation was based on varying the DCP loading from 0 to 0.9 parts per hundred parts of polymer (phpp) at 0.1 phpp intervals. The composite at DCP loading of $0.3 \mathrm{phpp}$ indicated the highest physicomechanical properties, gel content, the hardness of gel, and degree of crystallinity and the lowest degree of swelling. Properties of the composites with DCP were better than those of the control (without DCP). Water absorption decreased with the addition of DCP up to 0.3 phpp and increased after that with the rise in DCP loading. Scanning electron microscopic (SEM) image of the composite at $D C P$ loading of 0.3 phpp revealed a smooth fracture surface. Therefore, 0.3 phpp was identified as the optimum DCP loading for the NR/LDPE (70/30) composite.
\end{abstract}

Keywords: NR/LDPE composites, DCP, physico-mechanical properties, $\mathrm{CaCO}_{3}$, swelling behaviour 


\section{INTRODUCTION}

Thermoplastic elastomers (TPEs) are a class of polymeric materials that combine properties of rubbers with the ease of processability of thermoplastics. Natural rubber (NR)/low density polyethylene (LDPE) blend is an example of TPEs, but the two polymers are considered incompatible. Hence, curing agents and/or compatibilisers are necessary to reduce the incompatibility for better performance. A typical method for improving the compatibility and stabilisation of the phase morphology of a TPE is the dynamic vulcanisation. ${ }^{1}$ Dynamic vulcanisation process improves the properties of blends over the static vulcanisation process significantly. ${ }^{2,3}$

LDPE is a semi-crystalline material with a degree of crystallinity in the $50 \%-60 \%$ range, and hence, imparts several properties such as opacity, rigidity (stiffness), tensile strength, tear strength and chemical resistance. ${ }^{4}$ However, its use in blending with other polymers has been limited due to the absence of polar functional groups and the lack of reactive sites on the LDPE backbone. Chemical modification through functionalisation or grafting leads to an introduction of polar groups onto the LDPE backbone as pendant units or short chain branching. ${ }^{5}$ Organic peroxides generate free radicals on the LDPE backbone, and these radicals become reactive sites for grafting LDPE with another monomer/polymer or for crosslinking of LDPE. ${ }^{6}$ Use of organic peroxides for enhancing compatibility between polyethylene and ethylene vinyl acetate copolymer was successful. ${ }^{7}$ Also, 2,5-dimethyl-2,5-di-t-butyl peroxy hexane acted as a radical coupling agent for LDPE/polypropylene (PP) blends. ${ }^{8}$

The vulcanisation process of polymers by organic peroxides consists of three successive steps: (1) the haemolytic decomposition of peroxide and generation of free radicals; (2) the abstraction of hydrogen atom from the polymer chain resulting in stable peroxide decomposed products and polymer radicals; and (3) the combination of two polymer radicals to form a $\mathrm{C}-\mathrm{C}$ crosslink. ${ }^{9}$

Undesirable side reactions such as disproportionation and/or chain scission is a possibility during the vulcanisation process. The first step is the rate-determining step of the overall reaction. It is believed that the DCP initiates radical formation on LDPE backbone by hydrogen abstraction and chain scission as the chemical reaction as given in Figure 1. 


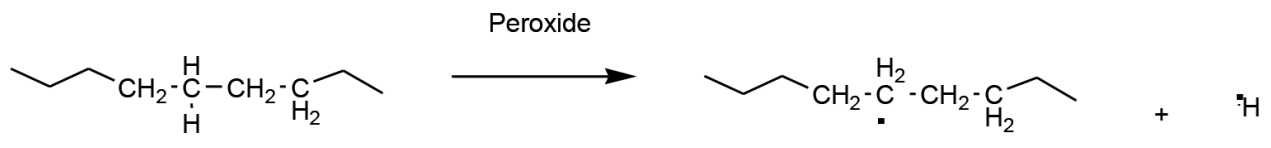

Figure 1: Radical formation on the LDPE backbone.

Many vulcanising agents such as sulphur peroxide and phenolic resin have been applied to vulcanise the rubber phase in the rubber-thermoplastic blends dynamically. ${ }^{10}$ Polybutadiene rubber (BR)/LDPE/polyvinyl chloride (PVC) $(75 / 25 / 15)$ blends were prepared with peroxide and sulphur vulcanising systems. ${ }^{11}$ It indicated that the physico-mechanical properties of the BR/LDPE/PVC blend significantly increased with the addition of a DCP loading of 1.225 phpp compared to those of the blend containing sulphur. This increase could be due to crosslinking of the LDPE phase by DCP. The NR/BR/LDPE blends at different compositions were prepared with a DCP loading of $2.7 \mathrm{phpp}$, and the BR/LDPE (90/10) and $\mathrm{NR} / \mathrm{BR} / \mathrm{LDPE}(60 / 30 / 10)$ blends indicated properties suitable for low-temperature applications. $^{12}$

Sulphur and peroxide vulcanising systems employed in ozonolysed NR/LDPE (40/60) blends revealed that the sulphur vulcanising system provides a higher degree of crosslink density than the peroxide vulcanising system, and attributed to improved damping and homogeneous phase morphology. ${ }^{13}$ However, the blends with the peroxide vulcanising system showed relatively enhanced tensile strength and elongation at break. Furthermore, tensile strength, elongation at break and damping properties of the blends vulcanised with both systems improved with the increasing ozonolysed NR content.

Sulphur (1.08 phpp) and peroxide (1.8 phpp)-combined vulcanising system has also been employed to vulcanise the elastomer phase of the NR/HDPE (60/40) blends as the vulcanising system combines the crosslink patterns of -S-S- and -C-S- linkages from sulphur and -C-C- linkages from peroxide. ${ }^{1}$ However, the most common vulcanising system is sulphur, used in various blends such as NR/ high-density polyethylene (HDPE), NR/polystyrene (PS), and ground tyre rubber (GTR)/LDPE blends. ${ }^{1,14,15}$

Crosslinking both NR and LDPE with peroxides including DCP is possible. However, DCP can form crosslinks in LDPE more efficiently than that to form crosslinks in NR. ${ }^{16}$ The NR/LDPE (25/75) blends vulcanised with DCP loading of 2 phpp has improved tensile strength and associated with crosslinking of the LDPE phase, and these blends showed no phase separation after boiled xylene extraction. ${ }^{16}$ Further, NR/LDPE (60/40) blends were prepared with DCP loading 
of $0.3 \mathrm{phpp}$ at different temperatures, and the effect of viscosity on properties of the blends was studied. ${ }^{17}$ The NR/LDPE (20/80) grafted blends with maleic anhydride (MAH) and acrylic acid, and with DCP loading of 0.3 phpp revealed grafting as a proper route to obtain enhanced properties. ${ }^{18}$ All these NR/LDPE blends verified that DCP is a promising vulcanising agent to use in the blends. However, these blends were prepared at a constant DCP loading, and the effect of DCP loading was not examined.

The preparation of rice husk $(\mathrm{RH})$ filled NR/LDPE composites in different compositions utilised DCP as the vulcanising agent and MAH as a compatibiliser. ${ }^{19}$ The NR/LDPE (25/75) blend with DCP loading of 1 phpp revealed increased Young's modulus and hardness but decreased tensile strength, elongation at break, impact strength and mass swell. No investigations were made with the NR/LDPE composites with other filler systems such as $\mathrm{CaCO}_{3}$. Most previously studied NR/ LDPE blends resulted in LDPE as the continuous phase.

The continuous phase changes from thermoplastic to rubber when rubber composition is approximately more than $65 \mathrm{wt} \%{ }^{20}{ }^{20}$ Therefore, this study focused on examining the effect of DCP loading on the mechanical, chemical, ageing and thermal properties, and morphology of the NR/LDPE (70/30) blend filled with $\mathrm{CaCO}_{3}$.

\section{EXPERIMENTAL}

\subsection{Materials}

The Rubber Research Institute of Sri Lanka supplied natural rubber (RSS-2) with a Plasticity Retention Index of 64. Deluxe Plastics Ltd., Sri Lanka, provided LDPE having melt flow index, density and crystalline melting temperature

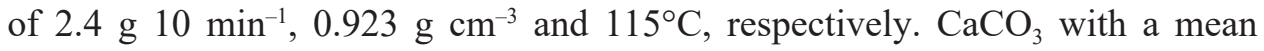
particle size of $2 \mathrm{~mm}$ and a density of $2.71 \mathrm{~g} \mathrm{~cm}^{-3}$, obtained from Lanka Minerals \& Chemicals (Pvt.) Ltd., Sri Lanka, acted as the filler. Sulphur and DCP were the vulcanising agents, stearic acid and zinc oxide $(\mathrm{ZnO})$ were the activator system, N-tert-butyl-2-benzothiazolesulfenamide (TBBS) was the accelerator, and 2,2'-methylene bis(4-methyl-6-tert butyl phenol) was the antioxidant (A/O) used in the composites preparation. These ingredients were of industrial grade and purchased from Glorchem, Sri Lanka. 


\subsection{Preparation of NR/LDPE Composite Compounds}

A series of NR/LDPE (70/30) composites was formulated by changing DCP loading from 0 phpp to 0.9 phpp. Table 1 presents the formulation of the composites, while the composite without DCP was the control. The preparation of composites involved melt-mixing using a Brabender plasticorder operated at $130^{\circ} \mathrm{C}$ and $60 \mathrm{rpm}$ rotor speed. Total mixing time remained constant at $14 \mathrm{~min}$. Table 2 presents the mixing cycle used to prepare the composite compounds.

Table 1: Formulation of NR/LDPE composite compounds.

\begin{tabular}{lc}
\hline Ingredient & (phpp) \\
\hline $\mathrm{NR}$ & 70 \\
LDPE & 30 \\
Zinc oxide & 05 \\
Stearic acid & 02 \\
$\mathrm{~A} / \mathrm{O}$ & 01 \\
$\mathrm{CaCO}_{3}$ & 20 \\
Sulphur & 0.5 \\
TBBS & 01 \\
DCP & $0,0.1,0.3,0.5,0.7,0.9$ \\
\hline
\end{tabular}

Table 2: Mixing cycle.

\begin{tabular}{cl}
\hline Time (min) & Added ingredient \\
\hline 0 & LDPE \\
4 & $\mathrm{NR}$ \\
6 & $\mathrm{ZnO}+$ Stearic acid $+\mathrm{A} / \mathrm{O}$ \\
7 & $1 / 2 \mathrm{CaCO}_{3}$ \\
9 & $1 / 2 \mathrm{CaCO}_{3}$ \\
11 & $\mathrm{TBBS}$ \\
12 & Sulphur $+\mathrm{DCP}$ \\
14 & Dumping the compound \\
\hline
\end{tabular}

NR/LDPE composites were compressed in an electrically heated hydraulic press at $150^{\circ} \mathrm{C}$ under 3.5 bar pressure for $15 \mathrm{~min}$ to produce $2 \mathrm{~mm}$ thick sheets. The processing conditions and compression moulding conditions were selected within the standard parameter ranges used to prepare NR/LDPE composites. ${ }^{21}$ Test specimens were stamped from the moulded sheets according to the standards. 


\subsection{Physico-mechanical Properties}

Determination of the tensile properties and tear strength of NR/LDPE composites was based on the Instron tensile testing machine according to BS ISO 37:2010 and BS ISO 34-1:2010, respectively. Dumbbell-shaped tensile test specimens and angle-shaped tear test specimens were used. Strain rate was maintained at $50 \mathrm{~mm} \mathrm{~min}^{-1}$, and the extension was measured as the separation of the crosshead. The hardness of the composites was determined using a dead load hardness tester according to BS ISO 48:2010, while the hardness of the gels after boiled p-xylene extraction was determined using a Shore A Durometer.

\subsection{Chemical Properties}

\subsubsection{Water absorption}

Test specimen with dimensions $30 \mathrm{~mm} \times 10 \mathrm{~mm} \times 2 \mathrm{~mm}$ was immersed in water at room temperature for $72 \mathrm{~h}$ to obtain water absorption, and the percentage increase in weight to the initial weight of the specimen was reported as the water absorption..$^{22}$

\subsubsection{Degree of swelling}

Test specimens with $30 \mathrm{~mm} \times 10 \mathrm{~mm} \times 2 \mathrm{~mm}$ dimensions were immersed in p-xylene for $72 \mathrm{~h}$ in closed-lid bottles as per ISO 1817:201. The degree of swelling $(Q)$ was calculated according to Equation 1:

$$
Q(\%)=\left(m-m_{0}\right) / m_{0} \times 100
$$

where $m_{0}$ and $m$ are the weights of the specimen before and after swelling respectively. Weights were recorded using an electric balance with $\pm 0.0001 \mathrm{~g}$ sensitivity.

\subsubsection{Gel content}

Test specimens with $1 \mathrm{~cm} \times 3 \mathrm{~cm} \times 0.2 \mathrm{~cm}$ dimensions and placed in a specimen holder were immersed in boiled p-xylene for $16 \mathrm{~h}$. The specimens were ovendried at $70^{\circ} \mathrm{C}$ until it reached the constant weight. ${ }^{22}$ Weights were measured to the nearest $0.1 \mathrm{mg}$. Percentage gel content $\left(Q^{\prime}\right)$ was calculated according to Equation $2: 23$

$$
Q^{\prime}(\%)-m_{1} / M \times 100
$$

where $\mathrm{M}$ is the initial weight of the specimen and $m_{1}$ is the weight of the ovendried gel. 


\section{$2.5 \quad$ FTIR Spectroscopy}

FTIR spectra of the oven-dried gels were obtained with the attenuated total reflectance (ATR) technique and a Nicolet 380 FTIR spectrometer. Spectra were recorded in the range of $400-3500 \mathrm{~cm}^{-1}$ operated at $4 \mathrm{~cm}^{-1}$ resolution.

\subsection{Thermal Ageing}

Retention of tensile properties was determined by heating the tensile specimens at $70^{\circ} \mathrm{C}$ for three days and calculations made as per Equation $3::^{24}$

$$
\text { Retention of tensile strength }=\frac{\text { Tensile strength obtained after ageing }}{\text { Tensile strength obtained before ageing }} \times 100
$$

\subsection{Morphology}

Surface morphology of tensile fracture surfaces of NR/LDPE composites was examined by SEM using a ZEISS EVO LS 15 microscope. The specimens were cut and mounted on aluminium stubs, and sputter coated with a thin layer of gold to avoid electrostatic charging during the examination.

\subsection{Thermal Properties}

The thermal properties of the NR/LDPE composites were examined by differential scanning calorimetry (DSC) using NETZSCH-DSC 204 F1 calorimeter. Approximately $10 \mathrm{mg}$ placed in an aluminium pan with a cover was scanned under a nitrogen atmosphere from room temperature to $150^{\circ} \mathrm{C}$. The melting temperature $\left(\mathrm{T}_{\mathrm{m}}\right)$ was determined as the peak temperature of the melting endotherm, and the enthalpy of fusion $\left(\delta H_{m}\right)$ was decided as the area of the melting endotherm. The degree of crystallinity $\left(X_{C}\right)$ was calculated according to Equation 4, via the total enthalpy method.

$$
X_{C}(\%)=\frac{\delta H_{m}}{\delta H_{m}^{0}} \times 100
$$

where $\delta H^{0}{ }_{m}$ is the enthalpy of fusion for $100 \%$ crystalline LDPE and taken as $288 \mathrm{~kJ} \mathrm{~kg}^{-1} .{ }^{25}$ 


\section{RESULTS AND DISCUSSION}

\subsection{Physico-mechanical Properties of NR/LDPE Composites}

Figure 2 illustrates the hardness of NR/LDPE composites at different DCP loadings. The hardness of all composites ranged between 55 and 65 IRHD. Hardness increases up to DCP loading of 0.3 phpp and decreases afterwards with the increase in DCP loading. It signifies an increase in hardness of $11 \%$ compared to the control, which contains sulphur alone as the vulcanising agent. Other composites contain sulphur and also DCP but at different loadings. Increase in the hardness of the composite with DCP loading of $0.1 \mathrm{phpp}$, compared to the control, could be due to the formation of additional cross-links in the NR phase with the addition of DCP. A remarkable increase in both gel content (Figure 10) and hardness of gel of the composite with DCP loading of 0.1 phpp (Figure 11) suggests an increase in the crosslink density in the NR continuous phase when DCP is added into the composite. A further rise in DCP loading up to $0.3 \mathrm{phpp}$ may have developed more cross-links in the NR phase and between NR and LDPE phases. It is believed that DCP initiates radical formation on the LDPE backbone by hydrogen abstraction and chain scission. ${ }^{26}$ The radicals then may react with sulphur cross-linked NR to form NR-LDPE linkages as in Figure 3.

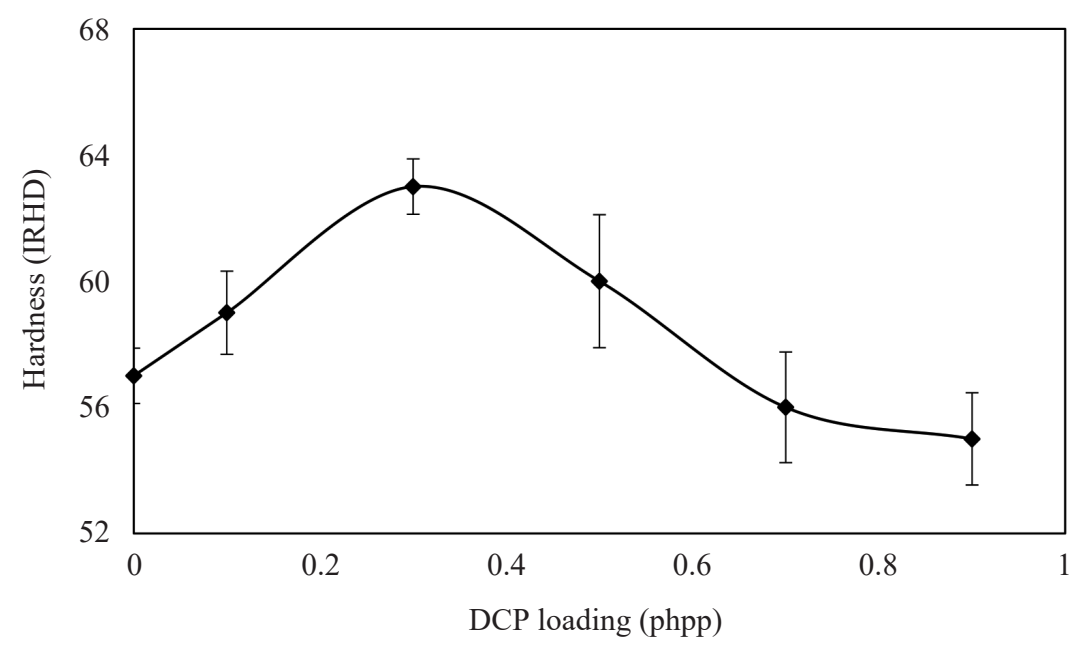

Figure 2: Hardness of NR/LDPE composites at different DCP loadings.

Crosslink decomposition is either radical or polar in character and generally operates at high temperatures. The decomposition will lead to a net loss in crosslink density and hence imparts reversion. ${ }^{27}$ Dissociation energies of bonds govern radical decomposition of polysulphidic crosslinks. Polysulphidic crosslinks, 
specifically S-S bonds of low dissociation energy, compared to C-C bonds, are easily dissociated. A previous study indicated that peroxides could act as chemical devulcanising agents for sulphur vulcanised rubbers as per mechanism presented in Figure $4 .{ }^{27}$ Hence, the highest hardness shown at 0.3 phpp DCP loading could be attributed to the highest crosslink density of the composite, and the presence of excess amounts of DCP could reduce the number of crosslinks formed.
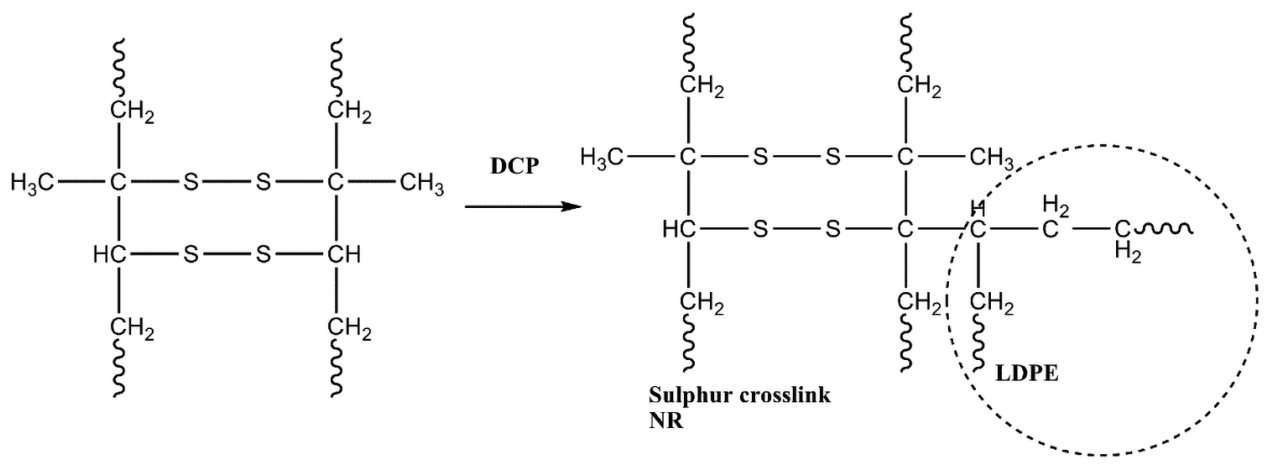

Figure 3: Possible reaction between NR and LDPE through DCP.

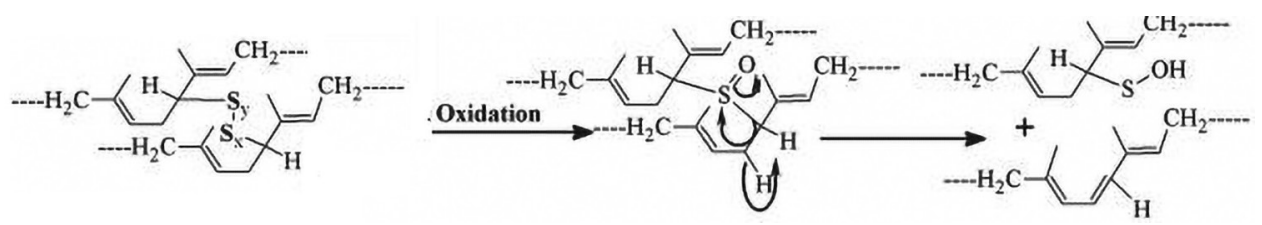

Figure 4: Mechanism of crosslink scission via oxidation of sulphur cross-linked rubber.

Stress-strain curves are a vital graphical measure of a material's mechanical properties such as tensile strength, modulus, elongation at break, and help to calculate Young's modulus and explaining material behaviour. Each type of material has its unique shape of a stress-strain curve. Stress-strain curves for NR/ LDPE (70/30) composites at all DCP loadings exhibit similar elastic behaviour as illustrated in Figure 5, suggesting that the continuous phase of the composites is NR. The elasticity increased with the incorporation of DCP at 0.1 phpp loading, indicating a possible association with the increase of crosslink density in the NR phase. Sulphur cross-linked rubber shows higher elasticity than DCP cross-linked rubber due to the presence of flexible polysulphidic crosslinks. ${ }^{24}$ DCP cross-linked rubber has mainly rigid $\mathrm{C}-\mathrm{C}$ crosslinks between the macromolecular chains. 


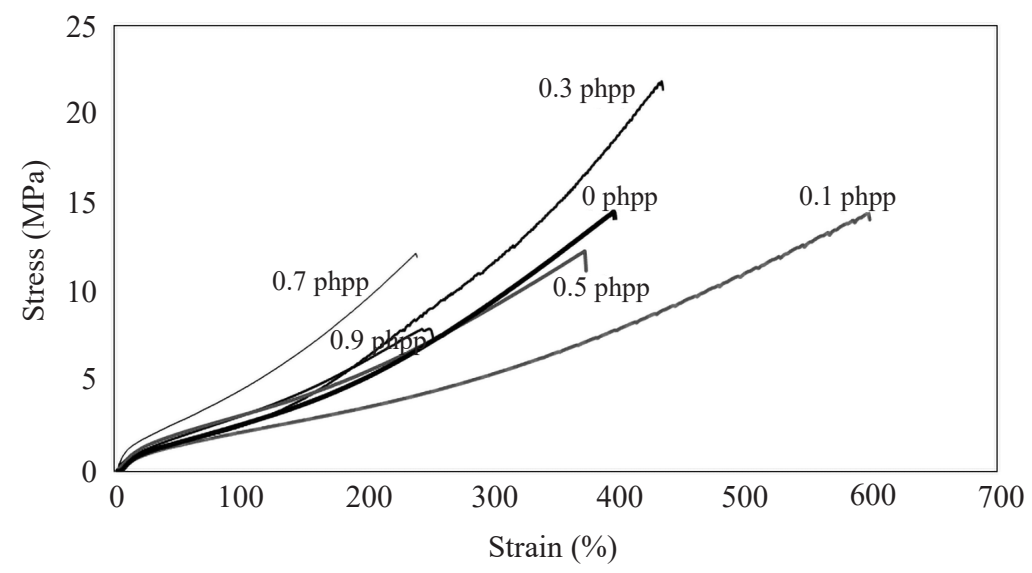

Figure 5: Stress-strain curves of NR/LDPE composites with DCP loading.

Figure 6 shows a marked increase in tensile strength from 0 phpp to $0.3 \mathrm{phpp}$ DCP loading followed by a decrease. The highest tensile strength is noted at the 0.3 phpp DCP loading, which may be associated with the highest crosslink density of the composite and/or with the highest degree of crystallinity of the LDPE phase during that DCP loading (see Table 4). Further, strong adhesion between NR and LDPE phases and lower surface tension at the interface could be expected as per reaction mechanism depicted in Figure $3 .{ }^{28}$ The crosslink density of the NR phase may decrease at higher DCP loadings while increasing the crosslink density of the LDPE phase. Highly cross-linked LDPE phase could prevent the formation of adhesions between phases, and may fail low elongations. A similar trend in tensile strength was reported for HDPE/GTR blends. ${ }^{7}$

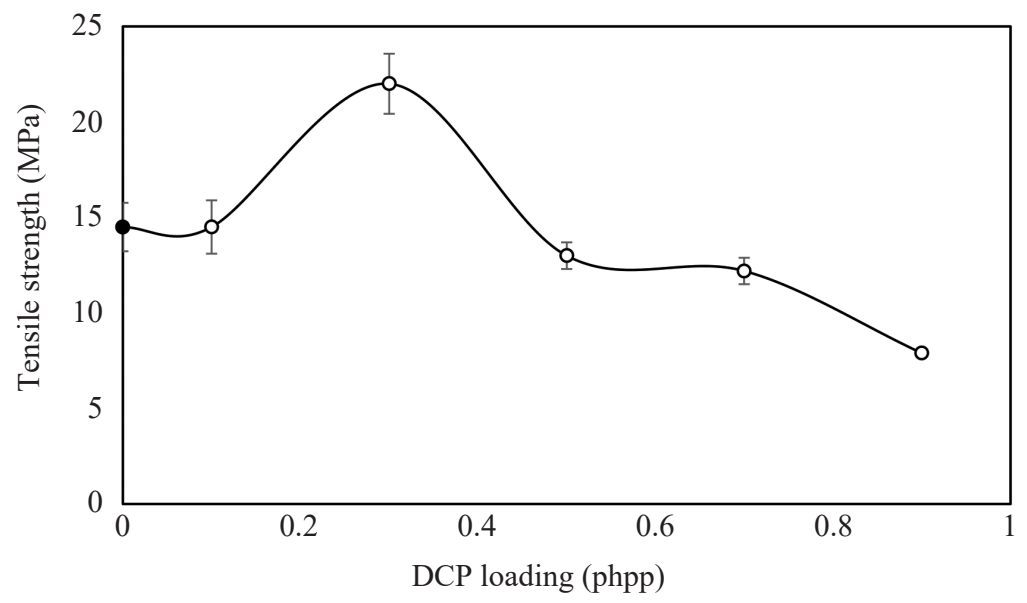

Figure 6: Tensile strength of NR/LDPE composites at different DCP loadings. 
Elastic elongation is due to uncoiling, untwisting and straightening of chains in the stress direction and indicates an amorphous behaviour of a material. ${ }^{28}$ Figure 7 shows an increase in elongation at break with the addition of $0.1 \mathrm{phpp}$ of DCP due to the presence of a higher degree of crosslink density, confirming that the added loading is insufficient to crosslink the NR phase in the composite. However, elongation at break gradually decreases with DCP loading from 0.1 phpp to 0.7 phpp with the crosslinking of the NR phase. Nevertheless, the variation of elongation at break with DCP loading from 0.7 phpp to 0.9 phpp is insignificant, suggesting the elastic behaviour of the two composites is more or less similar.

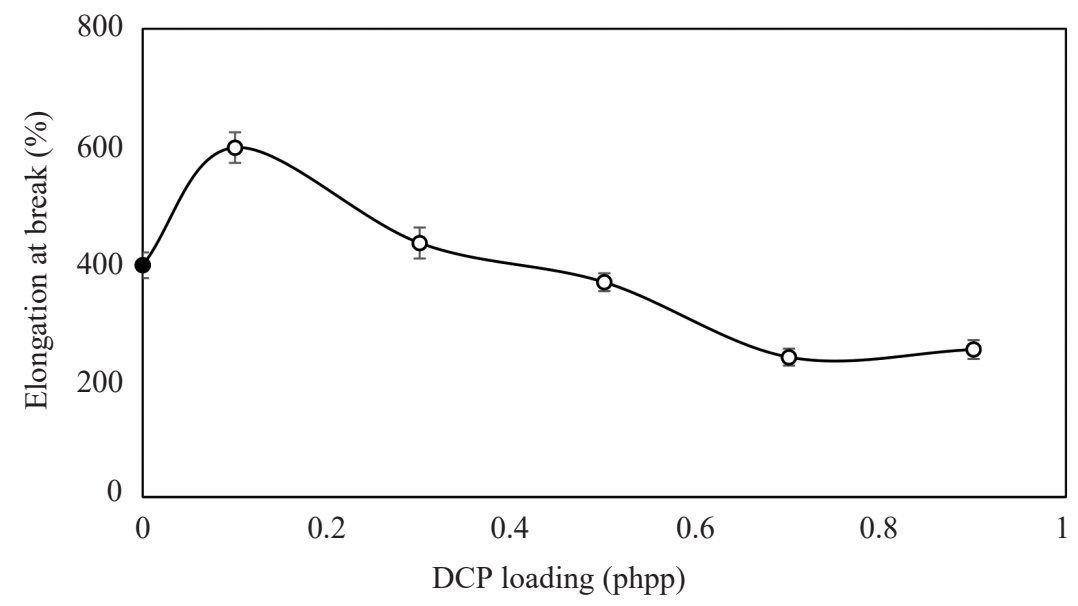

Figure 7: Elongation at break of NR/LDPE composites at different DCP loadings.

The tear strength is a valuable property that contributes to crack growth resistance. Tear strength of the composite at DCP loading of 0.3 phpp shows the maximum, as per Figure 8. High tear strength at DCP loading of 0.3 phpp may be attributed to the improvement of interfacial adhesion between NR and LDPE, which could reduce crack propagation during tearing. The mechanical properties of the HDPE/GTR blends were also reported to be improved significantly at $0.3 \mathrm{pphp}$ DCP loading. ${ }^{7}$ As expected, composites at all DCP loadings showed high tear strength compared to the control. The hardness of the composites (Figure 2) indicated a higher crosslinking density at $0.3 \mathrm{pphp}$ DCP loading. 


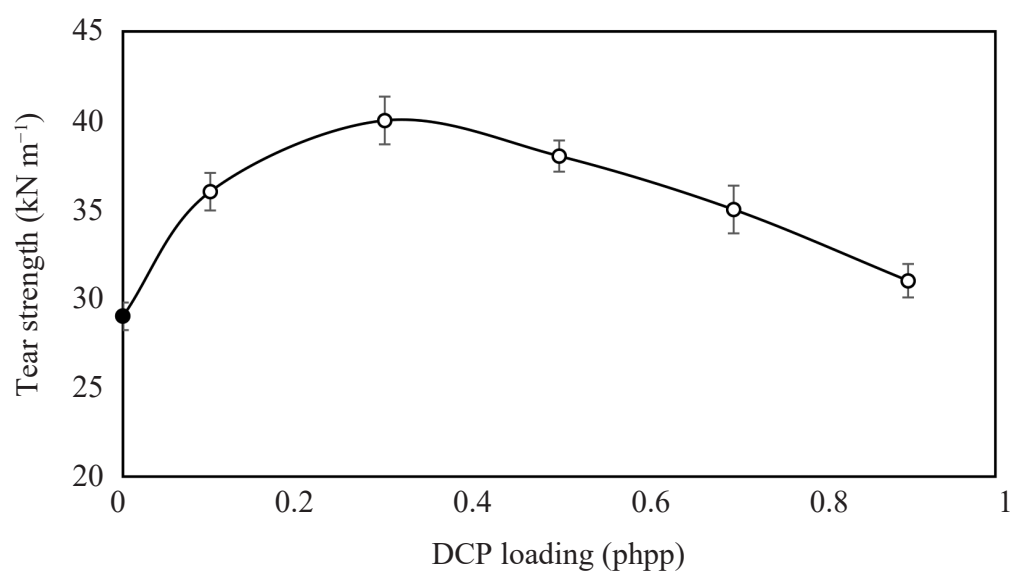

Figure 8: Tear strength of NR/LDPE composites at different DCP loadings.

\subsection{Degree of Swelling and Gel Content of NR/LDPE Composites}

The swelling property of a thermoplastic elastomer defines the chemical or liquid absorption capacity of that material. According to Figure 9, the degree of swelling decreases with increase in DCP loading up to $0.3 \mathrm{phpp}$, and increases thereafter up to $0.7 \mathrm{phpp}$. There is no significant variation shown with DCP loading from $0.7 \mathrm{phpp}$ to $0.9 \mathrm{phpp}$. The total number of chemical cross-links and trapped chain entanglements determined the crosslink density of the rubber phase, the latter depending on the entanglement density of the rubber during crosslinking. However, the ability of the NR phase to swell is limited by the degree of crosslinking of the NR phase; it is also imposed by the rigid LDPE phase, presenting the influence of the morphology on the degree of swelling. However, it was reported that the swelling properties of polymers are mainly related to the elasticity of the network, the extent of crosslinking, and the porosity of the polymer. ${ }^{29}$

Gel content helps to determine the solvent resistance of a thermoplastic or a rubber and known to be directly proportional to the crosslink density. Figure 10 presents the gel content of the control and the composites at different DCP loadings. The gel contents of all composites exhibit higher values compared to the control, confirming that DCP generated more cross-links in the NR phase of the composites. DCP loading of 0.3 phpp provided the maximum gel content, but the variation of gel content with the DCP loading is insignificant. A higher degree of swelling (Figure 9) with constant gel content for the composites with $0.7 \mathrm{phpp}$ and 0.9 phpp DCP loading proposes some porosity in the composite. This may be due to the separation of two phases due to the crosslinking of the LDPE phase at a greater extent with no adhesions between phases. 


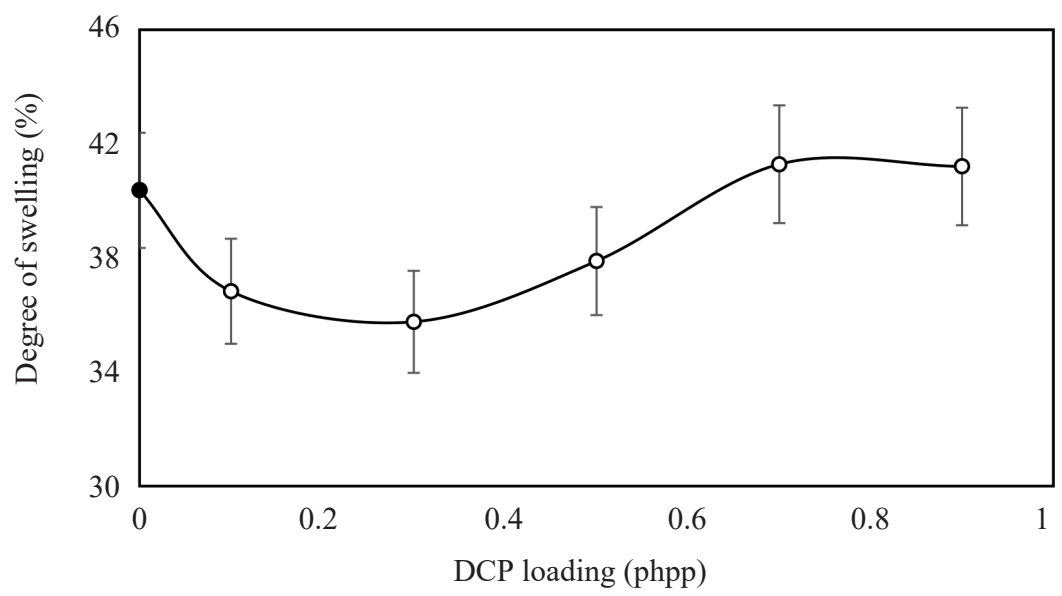

Figure 9: Degree of swelling of NR/LDPE composites at different DCP loadings.

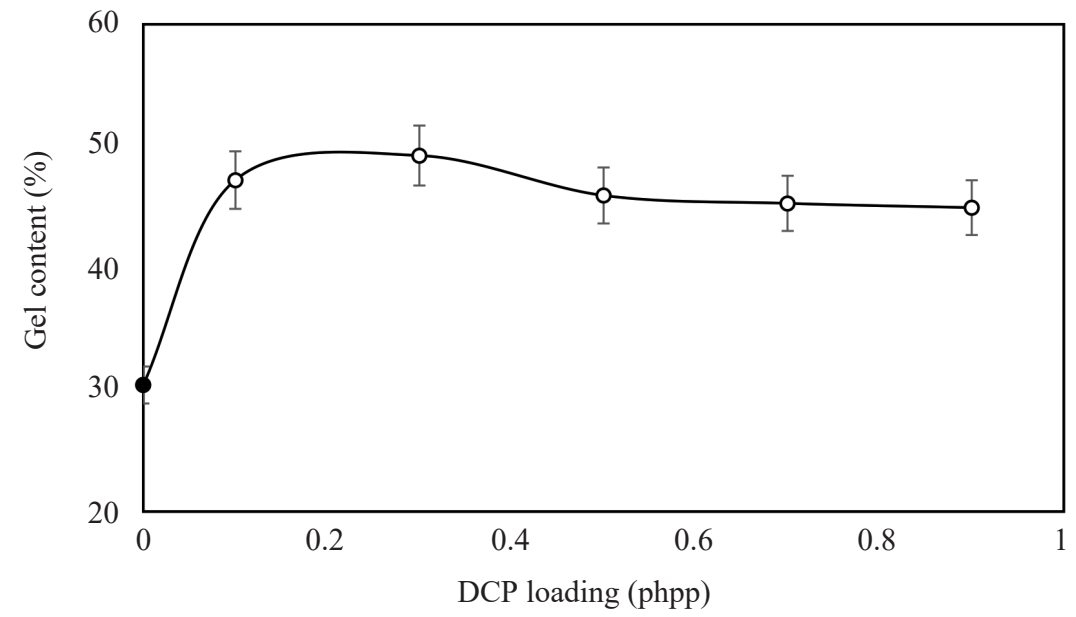

Figure 10: Gel content of NR/LDPE composites at different DCP loadings.

Figure 11 illustrates the hardness of gel composites with different DCP loadings. Hardness of gel increases significantly with the addition of DCP due to crosslinking of the NR phase and lies below 50, proposing that the gel mainly consist of crosslinked NR phase; hence, hardness of gel result is in agreement with stress-strain characteristics and hardness of the composites, and confirms that NR is the continuous phase of the composites. ${ }^{30}$ The hardness of gel decreases when DCP loading is at 0.7 phpp and further decreases at 0.9 phpp and is associated with the lower crosslink density of the NR phase due to devulcanisation with higher DCP loadings (Figure 4) and porosity in the composites. 


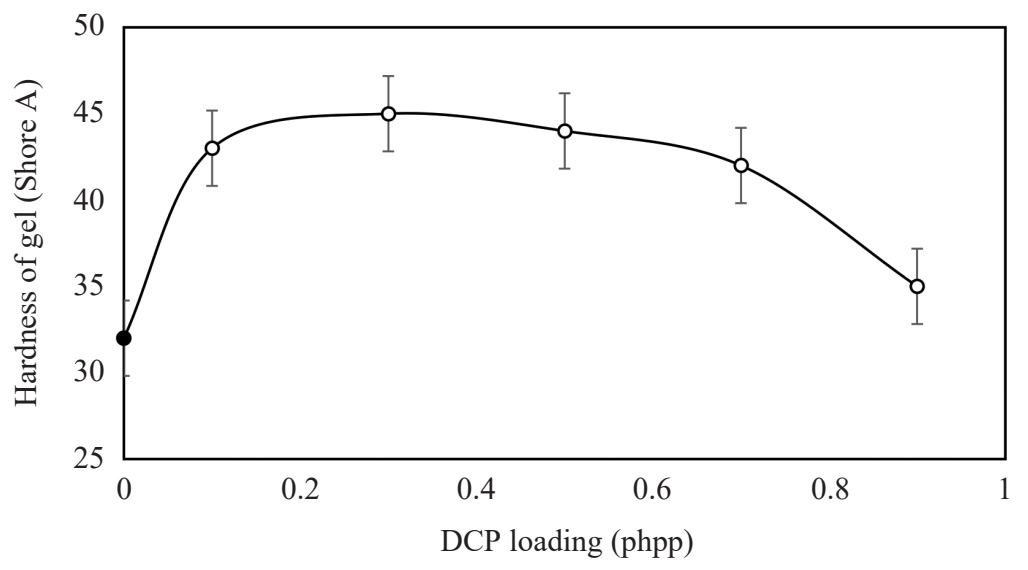

Figure 11: Hardness of gel content of NR/LDPE composites at different DCP loadings.

\subsection{FTIR Spectroscopic Analysis}

Figure 12 presents the FTIR spectra of raw NR, the gel of the control, and gels of the composites at different DCP loadings. S-S linkages generally reveal a weak stretching band in the 500-400 $\mathrm{cm}^{-1}$ range. ${ }^{31}$ One sharp peak at $430 \mathrm{~cm}^{-1}$ is for the gel of the control and is assigned to stretching vibration of S-S bonds, shown in Figure 12(a). This peak is not visible in the spectra of the gels of the composites with DCP, suggesting that no significant level of S-S crosslinks was present in the composites with DCP. This is associated with the S-S crosslink scission by DCP as per the mechanism in Figure 4. Spectra of the gels indicate a medium strong peak and a weak peak at $798 \mathrm{~cm}^{-1}$ and $823 \mathrm{~cm}^{-1}$, shown in Figure 12(b), which are attributed to stretching vibrations of C-S bonds and $\mathrm{H}-\mathrm{C}-\mathrm{S}$ bonds, respectively. These two peaks have not appeared in the spectrum of the raw NR. The gels of the composites with DCP exhibit two peak assignments in the range $690-700 \mathrm{~cm}^{-1}$, as seen in Figure 12(b). They are assigned to symmetric stretching vibrations of $\mathrm{C}-\mathrm{C}$ bonds. ${ }^{31}$ As expected, only one peak assignment is observed for the gel of the control, indicating the presence of C-S bonds (assigned to $694 \mathrm{~cm}^{-1}$ ) in the composite. According to Figure 12(d), a broader peak at $3440 \mathrm{~cm}^{-1}$, which is attributed to stretching vibration of $\mathrm{O}-\mathrm{H}$ bond, is exhibited in the spectrum of the gel of the composite at 0.3 phpp DCP loading. ${ }^{32}$ Further, the peak area at $1640 \mathrm{~cm}^{-1}$, which is assigned to stretching vibration of $\mathrm{C}=\mathrm{O}$ bond, is higher in the spectra for the gel of the composite at DCP loading of $0.3 \mathrm{phpp}$. The possible interaction given in Figure 3 supports the existence of O-H. Thus, the formation of these bonds proves that the composite at DCP loading of $0.3 \mathrm{phpp}$ achieved a better interaction between NR, LDPE, and other ingredients. This also would support increased gel content at 0.3 phpp DCP loading. 

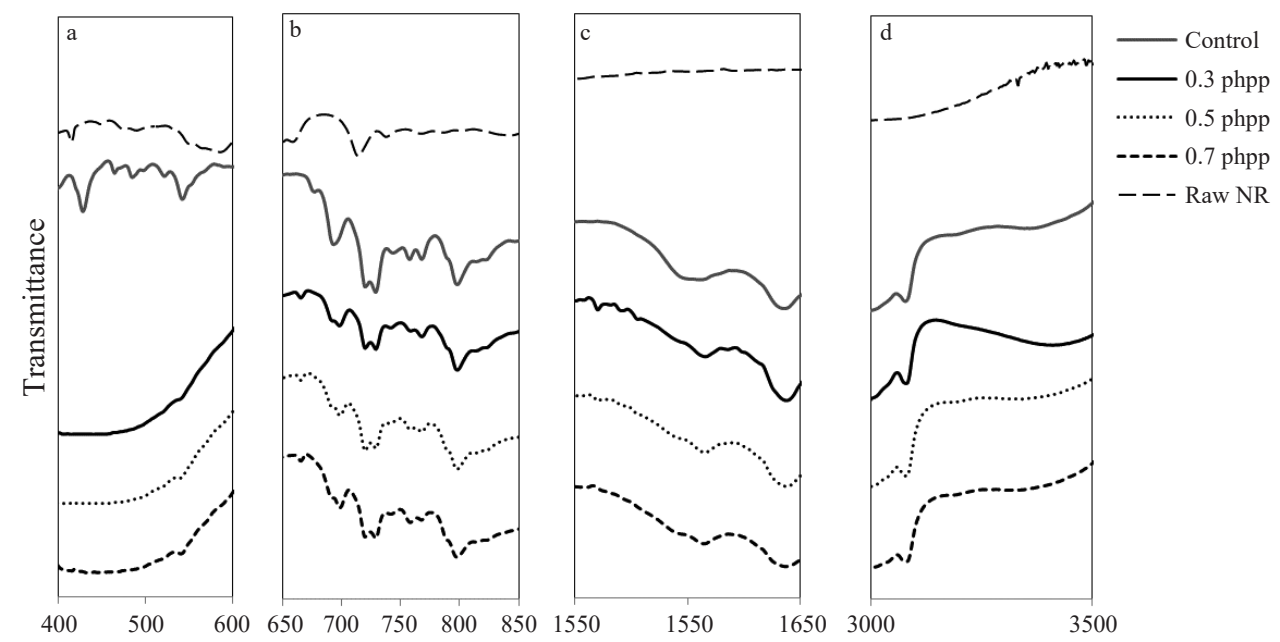

Wavenumber, $\mathrm{cm}^{-1}$

Figure 12: FTIR spectra of gels of the control and composites with DCP for different regions: (a) 400-600 $\mathrm{cm}^{-1}$, (b) $650-850 \mathrm{~cm}^{-1}$, (c) $1550-1700 \mathrm{~cm}^{-1}$, and (d) $3000-3500 \mathrm{~cm}^{-1}$.

\subsection{Thermal Ageing of NR/LDPE Composites}

Rubber-thermoplastic blends may degrade at elevated temperatures due to the oxidation process, and therefore its mechanical properties will decrease. Table 3 indicates that all composites containing either sulphur vulcanising system alone or with DCP are highly resistant to thermal degradation. Retention of mechanical properties was greater than $100 \%$ for the control and was $94 \%-97 \%$ for the other composites. This implies that the unreacted sulphur had undergone post vulcanisation when sulphur vulcanising system alone was present. ${ }^{33}$

Table 3: Ageing properties of NR/LDPE composites at different DCP loadings.

\begin{tabular}{ccc}
\hline $\begin{array}{c}\text { DCP loading } \\
\text { (phpp) }\end{array}$ & $\begin{array}{c}\text { Retention of tensile strength } \\
(\%)\end{array}$ & $\begin{array}{c}\text { Retention of elongation at break } \\
(\%)\end{array}$ \\
\hline 0 & 118 & 104 \\
0.1 & 95 & 97 \\
0.3 & 98 & 97 \\
0.5 & 95 & 98 \\
0.7 & 96 & 97 \\
0.9 & 94 & 96 \\
\hline
\end{tabular}




\subsection{Thermal Properties of NR/LDPE Composites}

Table 4 presents the glass transition temperature $\left(T_{g}\right), T_{m}$ and degree of crystallinity of composites. $\mathrm{T}_{\mathrm{g}}$ of NR increases with the addition of DCP loading of $0.1 \mathrm{phpp}$, confirming the formation of additional crosslinks in the NR phase by DCP. $\mathrm{T}_{\mathrm{g}}$ of NR further increases slightly, with DCP loading, exhibiting more cross-links in the NR phase. $T_{m}$ of LDPE also increases with the addition of DCP loading of $0.1 \mathrm{phpp}$ and is associated with the higher degree of crystallinity of the LDPE phase. With the crosslinking of the LDPE phase at higher DCP loadings, $T_{m}$ and the degree of crystallinity decreased. ${ }^{34}$ The highest degree of crystallinity is noted at the DCP loading of $0.3 \mathrm{phpp}$, and therefore, the composite at DCP loading of $0.3 \mathrm{phpp}$ demonstrates the highest tensile strength (Figure 6).

Table 4: Thermal properties of NR/LDPE composites at different DCP loadings.

\begin{tabular}{cccc}
\hline $\begin{array}{c}\text { DCP loading } \\
\text { (phpp) }\end{array}$ & $\begin{array}{c}\mathrm{T}_{\mathrm{g}} \\
\left({ }^{\circ} \mathrm{C}\right)\end{array}$ & $\begin{array}{c}\mathrm{T}_{\mathrm{m}} \\
\left({ }^{\circ} \mathrm{C}\right)\end{array}$ & $\begin{array}{c}\text { Degree of crystallinity } \\
(\%)\end{array}$ \\
\hline 0 & -58.6 & 109.3 & 16.6 \\
0.1 & -56.8 & 110.0 & 19.5 \\
0.3 & -56.5 & 110.8 & 20.8 \\
0.5 & -56.4 & 110.5 & 18.9 \\
0.7 & -56.3 & 109.8 & 15.2 \\
0.9 & -55.9 & 108.3 & 15.6 \\
\hline
\end{tabular}

\subsection{Water Absorption of NR/LDPE Composite}

As per Figure 13, water absorption of the composites is less than $55 \%$. Water absorption decreases with the addition of DCP loading of $0.1 \mathrm{phpp}$, and further declines up to DCP loading of 0.3 phpp. NR and LDPE are organic polymers, and hence they do not react with inorganic water molecules. The lowest water absorption at DCP loading of 0.3 phpp confirms a good adhesion between NR and LDPE phases of the composites at that DCP loading. Poor interfacial adhesion creates porosity at the interface and absorbs more water at higher DCP loadings. ${ }^{35}$

\subsection{Morphological Analysis of NR/LDPE Composites}

The relation between structure and properties of rubber-thermoplastic blends is complex as it depends on many parameters. ${ }^{36}$ Figures $14(\mathrm{a}-\mathrm{c})$ depict tensile fracture surfaces of the control and the composites at DCP loadings of 0.3 phpp and 0.9 phpp. The fracture surface of the control is rough, shown in Figure 14(a), while that of the composite at DCP loading of 0.3 phpp is smooth, seen in Figure 14(b). 


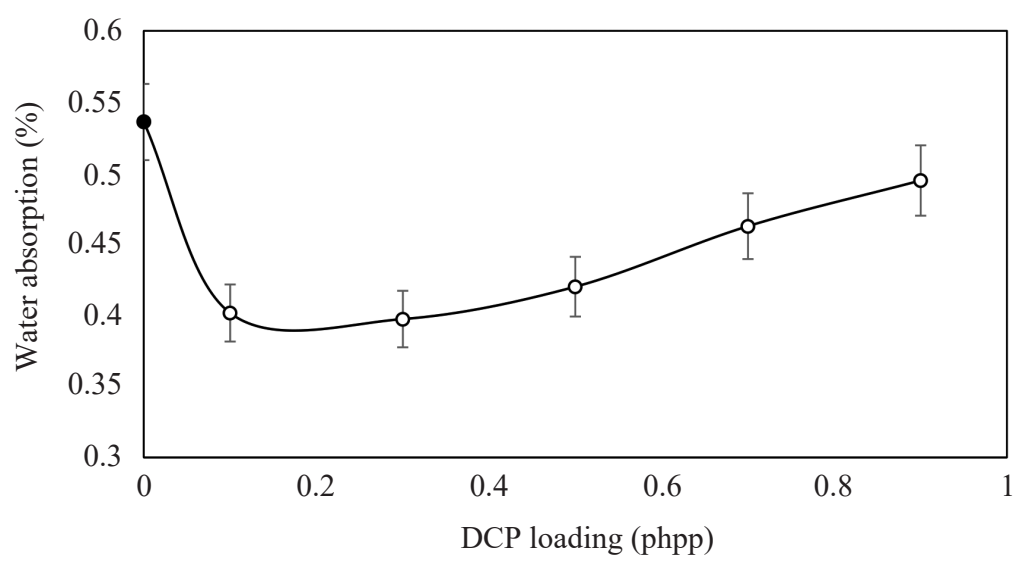

Figure 13: Water absorption of composites at different DCP loadings.
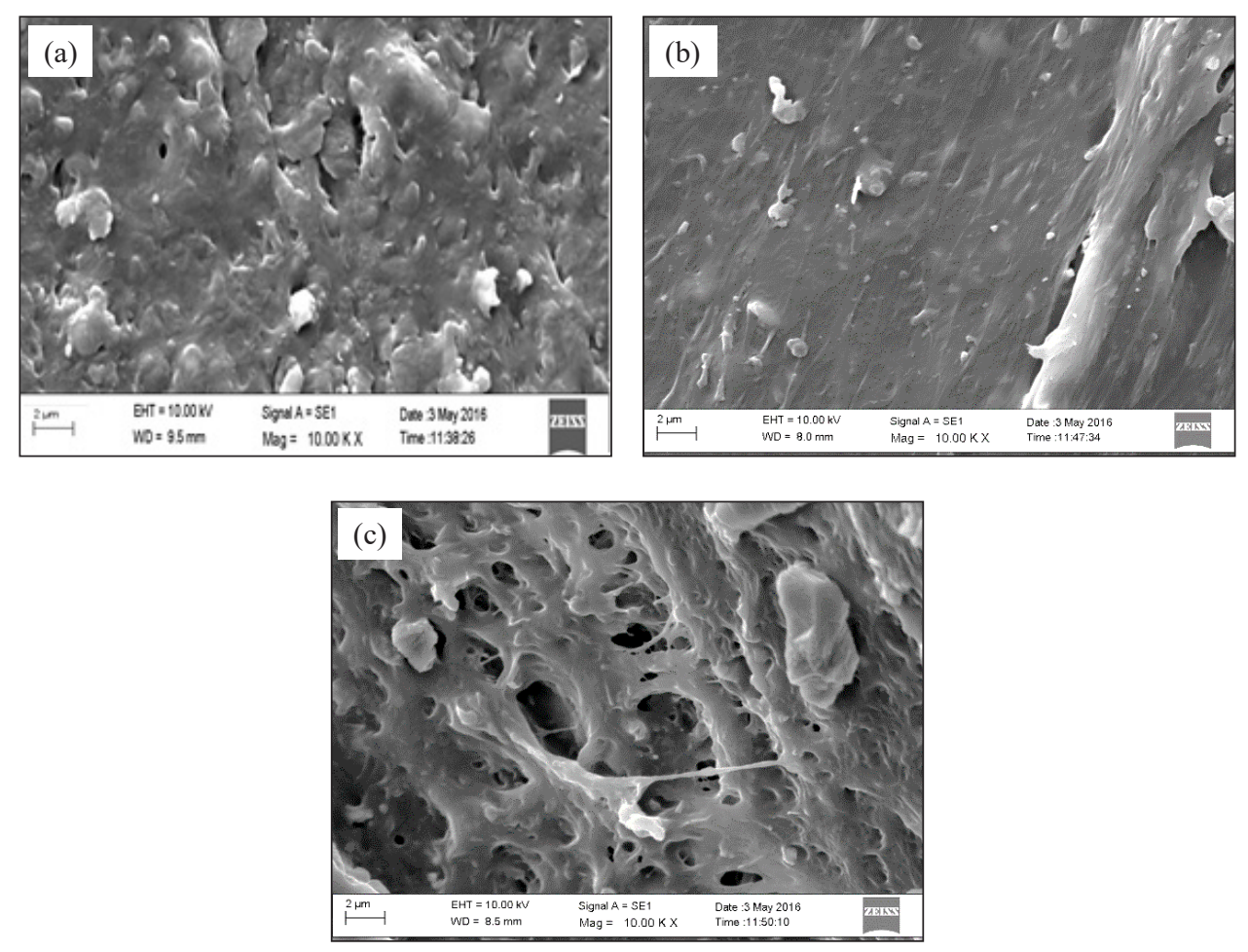

Figure 14: SEM images of tensile fracture surfaces of composites with DCP loading at10K magnifications for: (a) control, (b) 0.3 phpp, and (c) 0.9 phpp. 
This smooth fracture surface indicates a good adhesion between phases. The stronger interfacial adhesions provide more strength during tensioning, and poor crack propagation during tearing results in tensile strength and tear strength of the composite. However, the fracture surface of the composite at DCP loading of 0.9 phpp shows rough fracture along with porosity in the composite, shown in Figure 14(c). This could be the reason for poor tensile strength, tear strength, low gel content, and high water absorption of the composites at higher DCP loadings.

\section{CONCLUSION}

Hardness, tensile strength and tear strength of the NR/LDPE (70/30) composites increased with the addition of DCP up to $0.3 \mathrm{pphp}$ loading and then decreased with the increase in DCP loading. The gel content of the composites containing DCP lies in the range 45-50 IRHD, while that of the control was 30 IRHD, thus confirming additional crosslink formation by DCP in the NR phase. The lowest degree of swelling of the composite at DCP loading of 0.3 phpp indicates a higher degree of crosslinking in the composite. The hardness of the gel of the composites with DCP remained constant at 45 Shore A up to DCP loading of 0.3 pphp and then decreased with the increase of DCP loading. Water absorption of the composites increased with the increased DCP loading above 0.3 phpp. Further, the degree of crystallinity of LDPE phase increased with DCP loading up to $0.3 \mathrm{pphp}$ and subsequently decreased. This decrease in properties at higher DCP loadings is associated with scission of sulphur crosslinks by DCP and development of porosity in the composites at higher DCP loadings. These findings are in line with the conclusions of the FTIR spectra and the SEM images of the composites. SEM image of the composite at DCP loading of 0.3 phpp shows a smooth fracture surface proposing a good adhesion between NR and LDPE phases. The DCP loading of 0.3 phpp provided the best properties of the composites, and hence, was identified as the optimum loading for the NR/LDPE (70/30) composites.

\section{ACKNOWLEDGEMENTS}

The authors wish to acknowledge the Rubber Research Institute of Sri Lanka, Samson Compounds (Pvt.) Ltd, Pheonix Industries, and Lanka Minerals and Chemicals (Pvt.) Ltd., for supplying raw materials for the study. 


\section{REFERENCES}

1. Nakason, C. et al. (2006). Dynamic vulcanization of natural rubber/high-density polyethylene blends: Effect of compatibilization, blend ratio and curing system. Polym.Test.,25(6),782-796,https://doi.org/10.1016/j.polymertesting.2006.05.001.

2. Paul, D. R. \& Bucknall, C. B. (2000). Polymer blends, vol. 2. New York: Wiley.

3. Nwabunma, D. \& Kyu, T. (2008). Polyolefin blends. New Jersey: WileyInterscience, https://doi.org/10.1002/9780470199008.

4. Billmeyer, F. W. (1971). Textbook of polymer science. New Jersey: WileyInterscience, https://doi.org/10.1002/pi.4980040109.

5. Singh, S. K. et al. (2006). Maleic acid grafted low density polyethylene for thermally sprayable anticorrosive coatings. Prog. Org. Coat., 55(1), 20-26, https://doi.org/10.1016/j.porgcoat.2005.09.007.

6. Ghosh, P. \& Dev, D. (1998). Reactive processing of polyethylene: Effect of peroxide-induced graft copolymerization of some acrylic monomers on polymer structure melt rheology and relaxation behaviour. Eur. Polym. J., 34(10), 15391547, https://doi.org/10.1016/s0014-3057(97)00278-4.

7. He, M. et al. (2015). Effect of dicumyl peroxide and phenolic resin as a mixed curing system on the mechanical properties and morphology of TPVs based on HDPE/ground tire rubber. Polym. Compos., 36(10), 1907-1916, https://doi. org/10.1002/pc.23099.

8. Saki, T. A. (2015). Reactive melt blending of low-density polyethylene with poly (acrylic acid). Arab. J. Chem., 8(2), 191-199, https://doi.org/10.1016/j. arabjc.2011.05.021.

9. Hofmann, W. (1987). Cross-linking agents in ethylene: Propylene rubbers. Kauts. Gum. Kunst., 40(4), 308-332.

10. Nakason, C., Worlee, A. \& Salaeh, S. (2008). Effect of vulcanization systems on properties and recyclability of dynamically cured epoxidized natural rubber/ polypropylene blends. Polym. Test., 27(7), 858-869, https://doi.org/10.1016/j. polymertesting.2008.06.011.

11. Borah, J. (2013). Study on the compatibility and mechanical properties of BRLDPE-PVC blends. Paper presented at the 4th International Conference on Biology, Environment and Chemistry, Singapore.

12. Srilathakutty, R., Joseph, R. \& George, K. E. (2000). Development of polybutadiene (BR)-polyethylene (LDPE) blend based microcellular soles for low-temperature applications. J. Appl. Polym. Sci., 76(3), 277-281, https://doi.org/10.1002/ (sici)1097-4628(20000418)76:3\%3C277::aid-app1\%3E3.0.co;2-y.

13. Utara, S. \& Boochathum, P. (2011). Novel dynamic vulcanization of polyethylene and ozonolysed natural rubber blends: Effect of curing system and blending ratio. J. Appl. Polym. Sci., 120(5), 2606-2614, https://doi.org/10.1002/app.33466.

14. Asaletha, R., Kumaran, M. G. \& Thomas, S. (1999). Thermoplastic elastomers from blends of polystyrene and natural rubber: morphology and mechanical properties. Eur. Polym. J., 35(2), 253-271, https://doi.org/10.1016/s0014-3057(98)00115-3. 
15. Kumar, C. et al. (2002). LDPE-based thermoplastic elastomers containing ground tire rubber with and without dynamic curing. Polym. Degrad. Stab., 76(1), 137144, https://doi.org/10.1016/s0141-3910(02)00007-1.

16. Maziad, N. A., El-Nashar, D. E. \& Sadek, E. M. (2009). The effects of a silane coupling agent on properties of rice husk-filled maleic acid anhydride compatibilized natural rubber/low-density polyethylene blend. J. Mater. Sci., 44(10), 2665-2673, https://doi.org/10.1007/s10853-009-3349-3.

17. Poolsawat, K. et al. (2011). Effects of viscosity on properties of thermoplastic natural rubber (TPNR) prepared from natural rubber (NR) and low density polyethylene (LDPE). Paper presented at the Kasetsart University Annual Conference, Bangkok (Thailand), 1-4 Feb.

18. Patel, G. V. et al. (2006). A study on grafting of natural rubber and nitrile rubber on thermoplastic low density polyethylene using maleic anhydride and acrylic acid. Int. J. Polym. Mater., 55(6), 413-424, https://doi.org/10.1080/00914030500496932.

19. Maziad, N. A., El-Nashar, D. E. \& Sadek, E. M. (2009). The effects of a silane coupling agent on properties of rice husk-filled maleic acid anhydride compatibilized natural rubber/low-density polyethylene blend. J. Mater. Sci., 44(10), 2665-2673, https://doi.org/10.1007/s10853-009-3349-3.

20. Abdou-Sabet, S., Puydak, R. C. \& Rader, C. P. (1996). Dynamically vulcanised thermoplastic elastomers. Rub. Chem. Technol., 69(3), 476-494, https://doi. org/10.5254/1.3538382.

21. Karger-Kocsis, J., Mészáros, L. \& Bárány, T. (2013). Ground tyre rubber (GTR) in thermoplastics, thermosets, and rubbers. J. Mater. Sci., 48(1), 1-38, https://doi. org/10.1007/s10853-012-6564-2.

22. Zhu, S. et al. (2016). Effects of the incorporation of nano-bamboo charcoal on the mechanical properties and thermal behavior of bamboo-plastic composites. Bio. Res., 11(1), 2684-2697, https://doi.org/10.15376/biores.11.1.2684-2697.

23. Bengtsson, M., Gatenholm, P. \& Oksman, K. (2005). The effect of crosslinking on the properties of polyethylene/wood flour composites. Compos. Sci. Technol., 65(10), 1468-1479, https://doi.org/10.1016/j.compscitech.2004.12.050.

24. Noriman, N. Z. \& Ismail, H. (2012). Effect of epoxidized natural rubber on thermal properties, fatigue life, and natural weathering test of styrene butadiene rubber/ recycled acrylonitrile-butadiene rubber (SBR/NBRr) blends. J. Appl. Polym. Sci., 123(2), 779-787, https://doi.org/10.1002/app.34501.

25. Saci, H. et al. (2016). Reversible crosslinked low density polyethylenes: Structure and thermal properties. J. Polym. Res., 23(4), 1-9, https://doi.org/10.1007/s10965016-0965-x.

26. Maziad, N. A., El-Nashar, D. E. \& Sadek, E. M. (2009). The effects of a silane coupling agent on properties of rice husk-filled maleic acid anhydride compatibilized natural rubber/low-density polyethylene blend. J. Mater. Sci., 44(10), 2665-2673, https://doi.org/10.1007/s10853-009-3349-3.

27. Joseph, A. M. et al. (2016). The current status of sulphur vulcanization and devulcanisation chemistry: Devulcanisation. Rubb. Sci., 29(1), 62-100

28. Rector, Y. P. (2006). Polymers characteristics, applications and processing, 2nd ed. Virginia: University of Virginia. 
29. Abu-Abdeen, M. \& Elamer, I. (2010). Mechanical and swelling properties of thermoplastic elastomer blends. Mater. Des., 31(2), 808-815, https://doi. org/10.1016/j.matdes.2009.07.059.

30. Muzzy, J. D. (2009). Thermoplastics properties. Atlanta: Georgia Institute of Technology.

31. Rao, C. N. R., Venkataraghavan, R. \& Kasturi, T. R. (1964). Contribution to the infrared spectra of organosulphur compounds. Can. J. Chem., 42(1), 36-42, https://doi.org/10.1139/v64-006.

32. Silverstein, R. M., Bassler, G. C. \& Morrill, T. C. (1981). Spectrometric identification of organic compounds, 4th ed. New York: John Wiley and Sons.

33. Kumar, C. R., Fuhrmann, I. \& Karger-Kocsis, J. (2002). LDPE-based thermoplastic elastomers containing ground tire rubber with and without dynamic curing. Polym. Degrad. Stab., 76(1), 137-144, https://doi.org/10.1016/s0141-3910(02)00007-1.

34. Krupa, I. \& Luyt, A. S. (2002). Cross-linking of LDPE/wax blends in the presence of dicumyl peroxide. S. Afr. J. Chem., 55, 34-42.

35. Wang, S., Jiugao, Y. \& Jinglin, Y. (2005). Compatible thermoplastic starch/ polyethylene blends by one-step reactive extrusion. J. Polym. Int., 54(2), 279-285, https://doi.org/10.1002/pi.1668.

36. Paul, D. R. \& Barlow, J. W. (1980). Polymer blends. J. Macromol. Sci. C, 18(1), 109-168, https://doi.org/10.1080/00222358008080917. 